\title{
Essential Properties and Individual Essences
}

\begin{abstract}
According to Essentialism, an object's properties divide into those that are essential and those that are accidental. While being human is commonly thought to be essential to Socrates, being a philosopher plausibly is not. We can motivate the distinction by appealing — as we just did-to examples. However, it is not obvious how best to characterize the notion of essential property, nor is it easy to give conclusive arguments for the essentiality of a given property. In this paper, I elaborate on these issues and explore the way in which essential properties behave in relation to other related properties, like sufficient-forexistence properties and individual essences.
\end{abstract}

Essentialism, roughly put, is the view that an object's properties divide into those that are essential and those that are accidental. Being human, for instance, is commonly thought to be an essential property of Socrates, whereas being a philosopher would be accidental. There is disagreement in the literature on how best to characterize the notion of essential property and on which theories deserve the name 'essentialism' (§1). There is also disagreement on which properties are essential and also on whether essential properties are flexible-i.e., whether they allow for some variation from the actual world—or inflexible (§2). Many, but not all, would agree, however, that if $P$ is essential to $a$, then $P$ is a necessary condition for $a$ 's existence - that is, if being human is essential to Socrates, then it is a condition Socrates must satisfy for him to exist. Once we admit necessary conditions for $a$ 's existence, the question arises as to whether there are also sufficient conditions for $a$ 's existence and, more strongly, whether there are individual essences - that is, necessary and sufficient conditions for an object's existence (§3). Sufficiency properties interact with flexible essential propertiestypically more popular than inflexible ones-in a very particular way and, together, they yield flexible individual essences (§4).

Further issues to be discussed in relation to essentialism-but which fall beyond the scope of the present paper-include the following. First, one might wonder whether individual essences (whether flexible or not) set the basis for an ontological analysis-and understanding - of merely possible objects; like, for instance, a possible child of the (actually childless) Wittgenstein. Second, certain essentialist principles - the most popular ones-have consequences in relation to modal logic that essentialists dislike, and one might wonder how much room for manoeuvre there is. Third, the view that existence is necessary-known as 'necessitism'-requires a characterisation of essential property different from the ones I will consider here. I discuss these further issues in another survey in this journal ('Essentialism'). One final issue is epistemological: e.g., how do we know which properties are essential? For discussions on epistemological issues around essentialism, I refer the reader to Evnine and Vaidya. 


\section{Introduction to essentialism}

Roughly characterized, essentialism holds that, given an object, $a$, the set of its properties is the union of two disjoint sets: the set of essential properties, and the complementary set of accidental properties. For short, I shall call this rough characterization '(RC)'.

In this section, I will elaborate on (RC) by focusing on four different aspects: the characterization of essential property, the complementariness of the sets of essential and accidental properties, a terminological untidiness around 'essentialism', and different strengths of essentialism.

\subsection{What are essential properties?}

(RC) mentions essential properties without telling us what they are. The literature offers a range of answers to this question, not all of which are extensionally equivalent. ${ }^{1}$ Among them, two rival answers are (EMA) and (RDA):

Existential-Modal Account (EMA): $P$ is an essential property of $a$ if and only if $a$ could not exist without being $P$.

(Real-)Definitional Account (RDA): $P$ is an essential property of $a$ if and only if it helps answer the question: 'what is $a$ ?'. If $P$ is an essential property of $a, a$ could not exist without being $P$, but not the other way around.

These are the two main accounts that Fine explores in 'Essence and Modality'. On the side of (EMA), there is the fact that it seems to capture well enough what one might intend to mean by 'essential property'. Against it, however, there are a series of problematic cases that Fine takes to be knock-down counterexamples to (EMA).

A first problem is that the right-to-left direction of (EMA) - that is, the direction that tells us that if $a$ could not exist without $P$ then $P$ is an essential property of $a$-makes existence into an essential property (for, trivially, $a$ could not exist without existing) and this is widely accepted as a bad result. More pressingly, and equally convincingly, number 2 could arguably not exist without being the (sole) member of singleton $\{2\}$. Again according to the right-toleft direction of (EMA), therefore, being the (sole) member of singleton $\{2\}$ is essential to 2 . This, Fine complains, is also an unwelcome consequence. None of the problems Fine identifies against (EMA) challenge the left-to-right direction of (EMA). Far from it, according to the Finean (RDA), that direction holds: if a essentially Ps, then necessarily $\mathrm{Pa}$ (but not the other way around).

Fine's counterexamples to (EMA) have been widely accepted; to a degree that is unusual for philosophical arguments. ${ }^{2}$ The reason why virtually everyone agrees that being the (sole) member of $\{2\}$ is not essential to number 2 is, Fine suggests, because that property does not contribute to specify what being number 2 consists in. Granting that this is the reason, one can see why this also constitutes direct support for (RDA). ${ }^{3}$

It might be helpful to motivate at this point a distinction between trivial and non-trivial essential properties. Being self-identical or being $P$ or $\neg P$ are taken as trivial essential properties. Intuitively, they are essential properties that every object has. Since every object has them, they do not contribute to answer the 'what is $x$ ?' question in an informative

\footnotetext{
${ }^{1}$ For a compilation of different answers, see Robertson ('Essential vs. Accidental') and Yablo.

${ }^{2}$ Although see Correia ('(Finean) Essence') for a post-Finean defence of (EMA).

${ }^{3}$ It is worth mentioning that, while (RDA) is widely accepted, some metaphysical theories-most notably the ones known under 'necessitism' - cannot agree with it, since those theories cannot accommodate that if $a$ essentially $\mathrm{Ps}$, then necessarily $\mathrm{Pa}$. Zalta offers an explicit formulation of how necessitists can characterize the notion of essential property in a way congenial to the necessitist framework. For literature on Necessitism, see Linsky and Zalta (1994 and 1996) and Williamson 'Necessitism’.
} 
manner. The extension of 'trivial essential property' might differ across different characterizations of essential property. For instance, being such that $2+2=4$ is essential according to (EMA) and, since every object has it, it would also be trivial. By contrast, it might not be a trivial essential property according to (RDA) because it might not be essential to begin with.

\subsection{On complementariness}

(RC) is committed to (WC):

Weak complementariness (WC):

For any object, $a$, the essential/accidental distinction is exhaustive and exclusive relative to the set (or class) $C_{a}$ of $a$ 's properties.

We should distinguish (WC) from this other, stronger thesis:

Strong complementariness (SC):

Given the set (or class) $C$ of all properties, the essential/accidental distinction is exhaustive and exclusive relative to $C$.

Someone who does not think that the distinction is exhaustive to begin with will find both (WC) and (SC) wanting. ${ }^{4}$ For current purposes, however, it will make no harm to assume exhaustivity. Let us now see the difference between the two theses.

(WC) is implied by (SC), but not the other way around. Some essentialists think that the very same property $P$ might be essential to an object and accidental to another. Coincident entities-i.e., distinct entities occupying the same spatial region at least at some timeswould offer examples of such $P$ 's. Let $a$ be a statue with a particular shape, $s$, and let $m$ be the hunk of matter that constitutes $a$. Let $P$ be the property having shape $s$. While $P$ is plausibly essential to statue $a$, it is arguably not essential to hunk $m^{5}$ Similarly, Wilson suggests that being charged might be essential to electrons, but it is plausibly not essential to persons; and according to Martí and Martínez, being red might be essential to some natural substances or objects and yet accidental to others.

The properties having shape s, being charged, and being red are, therefore, potential counterexamples to (SC), but not to (WC). For, according to the examples, we cannot classify these properties, once and for all, as essential or accidental but do can classify them relative to a particular object.

\subsection{On 'essentialism':}

(RC) does not settle either whether, compatibly with essentialism, the set of essential properties or the set of accidental properties could be empty. There is disagreement in the literature as to what exactly deserves the name 'essentialism' ${ }^{6}$ Consider these three positions:

Pan-essentialism: all properties are essential.

Standard Essentialism: there are properties of both kinds.

Extreme Haecceitism: all properties are accidental (except for the trivial essential properties).

Some authors understand essentialism as being committed to the claim that (at least for some objects) both sets are non-empty and, as a result, would be ready to count neither panessentialism nor extreme haecceitism as essentialist positions. Here, I will be stipulatively

\footnotetext{
${ }^{4}$ As Robertson ('Essential vs Accidental') notes, one might want to say that there are properties for which the essential/accidental distinction simply does not apply; for instance, being such that 2 plus 2 equals 4 . Others, by contrast, think it is a desideratum of any theory of essence that the distinction applies universally (Correia, '(Finean) Essence' 63-64).

${ }^{5}$ This is a very illustrative example of how essentialism is put to work in metaphysical arguments. For a survey on material constitution see Wasserman.

${ }^{6}$ See Robertson ('Accidental vs. Essential Properties’).
} 
liberal with my use of 'essentialism' and allow each of these three initial positions to be rightly described as brands of essentialism. Without intending them to be conclusive to win a terminological debate, I will briefly mention my reasons for this liberalism. De re modalitythe phenomenon of objects being direct bearers of modal properties - is intimately related to essentialism. Without further ado: (EMA) collapses $P$ is essential to $a$ with $a$ bears $P$ necessarily; and, according to (RDA), if $P$ is essential to $a$ then a bears $P$ necessarily. Some are sceptical about de re modality (Della Rocca; Lewis; and Quine §41) ${ }^{7}$. However, neither pan-essentialism nor extreme haecceitism deny the existence of de re modality. On the contrary: according to the former, $a$ bears all of its properties necessarily, whereas according to the latter, $a$ bears all of its properties-except for the trivial essential ones-contingently. Because of this, and due to the intimate relation between, on the one hand, de re necessity and essentiality and, on the other, de re contingency and accidentality, I want to reserve the term 'anti-essentialism' to refer to the view that denies de re modality altogether. ${ }^{8}$

\subsection{Strengths of essentialism}

Each of the three initial positions above can be held either for all (kinds of) objects or for some of them and, therefore, the number of options increases accordingly. Pan-essentialism, when held for all objects, is the strongest in the spectrum of essentialist positions and is often attributed to Leibniz. At the other end of the spectrum, also when held for all objects, there is Extreme Haecceitism.

It is hard to find extreme haecceitists in the literature, probably because the position has strongly counterintuitive commitments; amongst them, 'my office chair could be a prime number' is true according to it. If we ask ourselves why this is so counterintuitive, a natural answer is that, no matter how liberal one is with respect to de re modality, the boundary between the concreta and the abstracta should be impermeable: nothing on the one side could be on the other. Despite the fact that we do not find extreme haecceitists, we do find philosophers like Penelope Mackie in How things might have been that come close. The only thing that prevents Mackie from being an extreme haecceitist is, precisely, that one of the very few constraints she imposes to de re modality is the concreta/abstracta impermeabilism thesis.

The majority of essentialists endorse one form or another of what I am calling 'standard essentialism' ('standard' for mere statistical reasons). Standard essentialisms can differ with respect to how many essentialist principles they hold, and whether they hold them universally (for all (kinds of) objects) or existentially (for some). In the next section, I will introduce the three most popular essentialist principles.

\section{Essentialist principles}

I will focus here on Essentiality of Origins, Sortal Essentialism, and Natural Kind Essentialism. I will offer, deliberately, very general formulations, partly because much of the discussions around them concern how best to articulate the intuitive idea behind those rough formulations.

\subsection{Essentiality of Origins (EO)}

Roughly, (EO) holds that origins are essential to originated entities. Let $s$ and $e$ be, respectively, the sperm and egg cell from which Ludwig Wittgenstein originated. According to (EO), it is essential to Wittgenstein to originate from $s$ and $e$. Intuitive support for (EO)

\footnotetext{
${ }^{7}$ Lewis can be classified as a sceptic about de re modality as a consequence of his inconstancy thesis (§4.5), although this is subject to controversy (Divers, §4).

${ }^{8}$ For a view critical of the relation between de re modality and essentialism, see Jubien.
} 
comes from what follows. Intuition seems to tell us that, given any pair of sperm and egg cell, $s^{*}$ and $e^{*}$, such that at least $s \neq s^{*}$ or $e \neq e^{*}$, any individual that could originate from $s^{*}$ plus $e^{*}$ would not be Wittgenstein, but someone else. Similarly, let $m$ be the hunk of matter from which a given table, $a$, originated, and let $m^{*}$ be a hunk of matter (possibly of the same kind of material, for instance wood) such that $m$ and $m^{*}$ do not overlap (i.e., they do not have any particle in common). Also in this case, intuition seems to tell us that any table we could construct from $m^{*}$ would not be $a$, but a different table.

The first case supports a more fine-grained version of (EO); namely, essentiality of biological origins for organisms. The second case supports another more fine-grained version of (EO); namely, essentiality of material origins for artefacts. It is worth noting that these two versions are logically independent; so each of them can be endorsed without commitment to the other.

(EO) - in its many different versions - has been extensively discussed in the literature, especially since Kripke's Naming and Necessity. Part of this discussion has centred in trying to offer arguments for some versions of it (e.g., Forbes The metaphysics of modality; Kripke; J. L. Mackie; P. Mackie, 'Identity'; and McGinn). Initial arguments have been objected normally by offering counterexamples to the target versions (e.g., Cameron; Salmon, Reference and essence; and Robertson 'Possibilities' and 'Essentialism'). In a rather concessive way, these objections have resulted in refined versions of (EO) intended to be immune to those counter-examples (e.g., Hawthorne and Gendler; Forbes 'Origins'; and Salmon, Reference and Essence). Some authors, however, find the potentially endless counterexample-rebuttal route unattractive, and have attempted to inaugurate new routes to (EO) (Rohbraugh and deRosset), to which some have objected too (Cameron and Roca; Damnjanovic; and Forbes and Robertson).

Versions of (EO) can be classified as strong (or rigid) or weak (or flexible). Let us see what the key difference is. Take again table $a$ and its actual original matter $m$. Let $F$ be the following inflexible (or rigid) property:

$F=$ being originally constructed from $m$.

Whereas the strong version holds that $F$ is essential to $a$, the weak version would replace $F$ with $F_{m}$, a flexible property:

$F_{m}=$ being originally constructed from a hunk of matter overlapping to a high degree with $m$.

When it comes to origin essentialism, flexibility is vastly more popular than rigidity. The intuition supporting weak-(EO) is that the very same object (be this a table, a chair, a tree, a human being, etc.) could intuitively originate from slightly different origins. This intuitionwhich the reader can test by considering table $a$ and hunks of matter $m$ and $m$ ', differing only in one single molecule-contradicts strong-(EO), which does not allow for any variation whatsoever in the origins.

Despite the fact that weak-(EO) has more intuitive appeal than its strong rival, it is often assumed to imply-due to Salmon (Reference and Essence, Appendix I)-the nontransitivity of the accessibility relation among possible worlds. This alleged implication, however, can be resisted. ${ }^{9}$

\subsection{Sortal (or Kind) Essentialism (SE)}

This principle holds that, if $k$ is the fundamental kind of a given object, $o$, then $o$ is essentially of kind $k$. According to Wiggins, an object's fundamental kind is the highest metaphysical kind under which the object falls and it gives us the most fundamental answer to the question 'what is it?' (Sameness and Substance 30). Socrates' fundamental kind is assumed to be

\footnotetext{
${ }^{9}$ See Williamson (Identity) and Roca-Royes ('Peacocke’s’ and ‘Essentialism’).
} 
human being. According to (SE), therefore, he is essentially human and, consequentlyaccording to both (EMA) and (RDA) - , he could not have been of a different kind.

Because (SE) is widely accepted amongst essentialists, there is not much literature hostile to it. The most notable exception is probably P. Mackie's attacks ('Sortal Concepts'; and How Things Might Have Been ch.7-8) on both Brody's and Wiggins' arguments for (SE).

(SE) and (EO) are logically independent. Consider again Wittgenstein and sperm $s$ and egg $e$ from which he originated. Wittgenstein being essentially human does not imply that he essentially originates from $s$ and $e$ : he could be human in all worlds where he exists, but originating from $s^{*}$ and $e^{*}$, different from $s$ and $e$, in some of them. Or, as Lowe suggests, he could be human without originating from any sperm and egg cell, originating instead ex nihilo (The Possibility of Metaphysics 152). So (SE) does not imply (EO). One might be inclined to think that (EO) implies (SE), but this is false too. ${ }^{10}$ Let me present an invalid argument that will help us see why (EO) does not imply (SE):

If (EO) is true, then Wittgenstein essentially originates from $s$ and $e$. Since $s$ is a human sperm and $e$ is a human egg cell, Wittgenstein is essentially human. There are at least two ways in which this argument is flawed. First, it implicitly assumes that $s$ and $e$ cannot be of a different kind. It therefore assumes (SE) in a version restricted to sperms and egg cells. ${ }^{11}$ If $s$ and $e$ could be, respectively, a dog sperm and a dog egg cell, then, Wittgenstein could be a dog while still originating from the "same" $e$ and $s$. So (EO) would be true while (SE) false, against the claim that the former implies the latter. Second, it implicitly assumes as well that, if Wittgenstein is born human, it cannot become of a different kind later on. A world where Wittgenstein originates from $s$ and $e$ and where he is born human but becomes a beetle at some point after his birth would also be a counterexample to (SE) but not to (EO). To turn the argument into a valid one we would therefore need some auxiliary premises. If we assumed that genetic information is essential to, and even individuative of, sperms and egg cells (which one might find independently plausible), then, this will probably ground (SE) for sperms and egg cells and, that being available, we could guarantee that Wittgenstein is born human, thereby blocking the first kind of scenario. If, in addition, we assumed that fundamental kinds obey the principle "once an $F$, always an $F$ ", then we would block as well the second kind of scenario. ${ }^{12}$

(EO), therefore, does not imply (SE). And while some might think that the two auxiliary premises are independently plausible, there are philosophers that deny them. Mackie (How Things Might Have Been ch.7), for instance, would deny the first one while Lowe (The Possibility of Metaphysics ch.8) suggests that the second one might plausibly fail.

\subsection{Natural Kind Essentialism (NKE)}

According to (NKE), if instances (or samples) of a given natural kind, $k$, have structure $x$ (be this microphysical structure, biological structure, chemical structure, etc.), then, it is essential to $k$ that all its instances (or samples) have structure $x$. (Contrast (NKE) with (SE): while it might be essential to natural kind $k$ that its instances have $x$, it might not be essential to actual instances of $k$ that they have $x$.)

We know-or normally assume-that the chemical structure of water is $\mathrm{H}_{2} \mathrm{O}$. It is also standardly assumed that water is a natural kind. If these assumed things are true, and if so is (NKE), then $\mathrm{H}_{2} \mathrm{O}$ is the essence of water. Similarly, let us assume that the biological structure

\footnotetext{
${ }^{10}$ I myself was under this impression in (Roca-Royes 2009).

${ }^{11}$ Note that this is insufficient to make the argument circular, though. For it assumes (SE) restricted to sperms and egg cells in an attempt to conclude (SE) for humans beings.

${ }^{12}$ This principle, as Mackie notes (How Things Might Have Been ch.7), is weaker than (SE).
} 
common to all cats is $x$. According to (NKE) — and if cat is a natural kind-it is essential to cat that all its instances have $x$.

Although (NKE) is — or has been for a while-widely accepted, one can find more and more literature hostile to it. There is an alive discussion, coming from the philosophy of biology (and especially since Dupré), around the implications that the truth of Darwinism would have for (NKE). Darwinism is often taken to imply that biological species have no essences. The controversy arises as to how to read this result. For it can be read as implying the falsity of (NKE), but it can also be read as implying that biological species are not natural kinds ${ }^{13}$ and, therefore, (NKE) would be immune to their not having essences. One could also challenge (as Devitt does) the thesis that gives rise to the controversy in the first place and defend instead the view that biological species do have essences.

At the interface between metaphysics and semantics, arguments for (NKE) have been offered appealing either to the rigidity of natural kind terms (Kripke) or to our intuitions about how we would apply natural kind terms in counterfactual scenarios (Putnam). For brevity, I will focus here on Putnam's motivations only. Let us consider a possible world, $w$, where there is no $\mathrm{H}_{2} \mathrm{O}$, but where some other liquid with chemical structure $\mathrm{XYZ}$ fulfils the $\mathrm{H}_{2} \mathrm{O}$-role. Samples of XYZ are macroscopically indistinguishable from samples of $\mathrm{H}_{2} \mathrm{O}$. Despite this, according to Putnam's widely shared intuitions, we wouldn't call XYZ 'water', even if $w$-inhabitants might do so. These intuitions are intended to support the claim that water is essentially $\mathrm{H}_{2} \mathrm{O}$ - as opposed to merely being contingently realized by $\mathrm{H}_{2} \mathrm{O}$ in our world - and, with it, an externalist semantics for natural kind terms. This line of thought, however, has its detractors. Salmon ('How not to derive') and Lowe ('A problem') have argued against Kripke's arguments-compatibly with the truth of their conclusions-that they can only establish (NKE) if, amongst the premises assumed (explicitly or implicitly), some of them are already non-trivially loaded with essentialist import. Mellor has also argued against Kripke's and Putnam's arguments and favours - contra (NKE) - a brand of internalism about the semantics of natural kind terms. According to internalism, (alleged) natural kind terms make reference to the macroscopic properties of substances like $\mathrm{H}_{2} \mathrm{O}$ or $\mathrm{XYZ}$ and, therefore, it is wrong to speak of "the" chemical structure of water. A recent defence of this view is due to Wikforss.

\section{Essential properties, sufficient-for-existence properties, and individual essences}

Essentialist principles are often endorsed together with sufficiency principles (Forbes, The Metaphysics of Modality; Kripke; McGinn; Peacocke; Salmon, Reference and Essence), although not always (P. Mackie; Rohbraugh and deRosset). While these two kinds of principles are metaphysically related, their directions oppose each other. As we saw above, even on (RDA) - the definitional account-an essential property imposes necessary conditions for the existence of individuals. By contrast, sufficiency principles state sufficient conditions. Here is, by way of an example, a candidate for being a sufficiency principle that Salmon endorses:

(SP) If it is possible for a table $x$ to be the only table [in a world] originally constructed (by a certain artisan in a certain place at a certain time) from a certain hunk of matter $y$ according to plan $P$, then necessarily, any table that is the only table [in a world] to be originally constructed (by the very same artisan in the very same place at the very same time) from the very same hunk of matter $y$ according to the very

\footnotetext{
${ }^{13}$ An alive alternative is (SAI) - the thesis that species are individuals (Hull; and Ghiselin). Another alternative is to consider them as sets (Kitcher). Yet another alternative is to consider them as Homeostatic Property Clusters (Boyd; and Millikan). For a discussion on natural kinds see Koslicki.
} 
same plan $P$ is the very same table $x$ and no other. (Reference and essence 229; my labeling)

Sufficiency principles are also known as cross-world identification principles. The reason is clear. If the output of a given artisan manufacturing a table from $y$, at a given place and time, and according to plan $P$ is necessarily table $x$, then, in any world where that table-making process is carried out, we can identify the resulting table as table $x$.

Not only do sufficiency and essentialist principles have opposite directions, but they also are logically independent. Consider again our table $a$ and its original matter $m$. Let us assume further that $a$ is made by artisan $A$, according to plan $P$, at time $t$ and place $p$. One could hold that all $m, A, P, t$, and $p$ are essential to $a$. According to both (RDA) and (EMA), this requires that in each possible world where a exists, a satisfies $C P$ :

$C P$ = being made from $m$, by artisan $A$, according to plan $P$, at time $t$ and place $p$.

However, this does not prevent there being other worlds where $a$ does not exist and such that something other than $a$ satisfies $C P$. Consequently, one can be essentialist about $C P$ while, consistently, not holding $C P$ to be a sufficient-for-existence property. Conversely, one can hold $C P$ as a sufficient-for-existence property while not being essentialist about it. Table $a$ might be the only object that can possibly satisfy $C P$ and it might also be a possible instantiator - and maybe also the only one-of $C P^{*}$ (different from $C P$ ). We will come back to this in $\S 4$.

Despite this logical independence, belief in essential properties and belief in sufficientfor-existence properties often come together. When they do, (some) sufficient-for-existence properties combine with (some) essential properties - or sets of them-to yield individual essences, characterized by Plantinga, roughly, as follows (70):

$I E$ is an individual essence of $x$ if and only if: $I E$ is essential to $x$ and, necessarily, any

object $y$ that exemplifies IE is identical to $x$.

Also despite the logical independence, one might think that (RDA) — the leading account on essential properties - is very naturally coupled with sufficiency principles. Let us assume that there are no sufficient-for-existence properties. Let $E P_{a}$ be the set of $a$ 's essential properties. By assumption, there is a world where an object, $b$, other than $a$, satisfies $E P_{a}$. If this is so, $E P_{a}$ is as good an answer to 'what is $a$ ?' as it is as an answer to 'what is $b$ ?'. One could therefore worry that "as good" is not good enough. $E P_{a}$ is not good enough to distinguish what it is to be $a$ from what it is to be $b$. As a result, (RDA) without sufficiency principles can at most aim at offering partial real definitions, and this might be thought to go against the spirit of (RDA).

It is a controversial matter whether individual essences should be expressible in purely qualitative terms-mentioning only individual-free properties and relations, unlike being Sam's daughter - or whether, by contrast, they cannot but involve other individuals. Forbes (The Metaphysics of Modality) aims at purely qualitative individual essences, whereas Plantinga postulates purely non-qualitative ones (like being Plantinga). ${ }^{14}$ Property $\mathrm{CP}$-if it were an individual essence-would be a neither purely qualitative one nor a purely nonqualitative one, since it involves hunk $m$ and artisan $A$, but also the relation being made from. Endorsement of this kind of hybrid individual essences is the most common to be found in the literature, partly due to the fact that essential properties are also normally given in nonpurely qualitative terms.

\footnotetext{
${ }^{14}$ Adams argues against purely qualitative individual essences, and so does P. Mackie ('Essence, Origin and bare Identity’ and How Things Might Have Been).
} 
When an individual essence-or an essential property-of an object $x$ irreducibly involves another object $y$, we say that $x$ ontologically depends on $y$. (The notion of ontological dependence is explained at length in (Correia, 'Ontological Dependence').)

\section{Individual essences vis-à-vis flexible essential properties}

Flexible essential properties interact in a very special-yet under-explored-way with sufficient-for-existence properties. Let us assume that $C P$ from the previous section is a sufficient-for-existence property:

$C P$ = being made from $m$, by artisan $A$, according to plan $P$, at time $t$ and place $p$.

If we were rigid essentialists about all of $m, A, P, t$ and $p, C P$ would be both essential to $a$ and sufficient for $a$ 's existence. Things are otherwise, however, if we endorse weak-(EO), which identifies $F_{m}$-instead of $F$, from $\S 2$ - as an essential property of table $a$ :

$F_{m}=$ being originally made from a hunk of matter overlapping to a certain (high) degree with $m$.

Let us assume that $m, m_{1}, m_{2}, m_{3}$ and $m_{4}$ are the only pieces of matter that overlap enough with $m$ for it to be possible that $a$ originates from any of them. For the sake of brevity of exposition, let us assume that $t, P, p$, and $A$ are rigidly essential to $a$.

While $C P$ is-by assumption-a sufficient-for-existence property for $a$, it is not an essential property, for $a$ could equally originate from $m_{1}$. Furthermore, since it is possible for $a$ to be the only table originated from $m_{1}, A, P, p$ and $t$, then, applying (SP)-Salmon's sufficiency principle from $\S 3$-we get that $C P_{1}$ is another sufficient-for-existence-property for $a$ :

$C P_{1}=$ being made from $m_{1}$, by $A$, according to plan $P$, at time $t$ and place $p$.

Similarly for the analogous $C P_{2}, C P_{3}$ and $C P_{4}$. By the definition of individual essence (§3)which requires an individual essence to be both essential and sufficient-none of $C P-C P_{4}$ are candidates for being individual essences. Nonetheless, this is not to say that there is no individual essence of table $a$. Let us assume that $C P-C P_{4}$ are the only sufficient-for-existence properties for $a$. In this case, $a$ is the only individual (possible or actual) such that: (i) it can be the instantiator of any of $C P-C P_{4}$; and (ii) it is the instantiator of $C P-C P_{4}$ in any world in which there is one such instantiator. Therefore, $I E_{a}$ is a good candidate for being $a$ 's individual essence:

$I E_{a}=$ originating from a hunk of matter overlapping to a high degree with $\boldsymbol{m}$, at $t$ and $p$, according to $P$ and by $A$.

$I E_{a}$, therefore, individuates table $a$, and this is well in line with the spirit of the notion of individual essence. Furthermore, it is a flexible individual essence (whose flexibility is directly inherited from the flexibility of $\left.F_{m}\right){ }^{15}$

A worry that arises from reflecting on flexible individual essences is as follows. Consider this property:

$I E_{\text {? }}=$ originating from a hunk of matter overlapping to a high degree with $\boldsymbol{m}_{\mathbf{1}}$, at $t$ and $p$, according to $P$ and by $A$.

Is there any (possible) object individuated, in our world, by $I E_{\text {? }}$ ? The friends of both sufficient-for-existence properties and flexible essential properties might be forced to make a choice of evils, instantiated in the literature by Williamson and Salmon. Assume first that there is one such object; call it ' $b$ '. Assume further that the sufficient-for-existence properties for $b$ are $C P_{1}-C P_{5}$ (and that $a$ 's are CP-CP ${ }_{4}$ ). Object $b$ is different from $a$ : $a$ is not, but $b$ is, a possible instantiator of $C P_{5}$. Both are, however, possible instantiators of $C P_{3}$. There are

\footnotetext{
${ }^{15}$ For a discussion on flexible individual essences, see Chisholm; Lewis; and P. Mackie 'Essence, Origin and Bare Identity’.
} 
worlds, therefore, where $b$ is the instantiator of $C P_{3}$, and different worlds where $a$ is the instantiator of $C_{3}$. If this is so, however, $C P_{3}$ is a sufficient-for-existence property of neither, against the second assumption. To avoid this, one might be willing to accept that, while $I E_{a}$ individuates an object (at least in our world), $I E_{\text {? }}$ does not, despite the fact that they are analogous. This is Salmon's choice (Reference and Essence, and 'The Logic'). For him, the argument just given is a reductio of the first assumption.

For Williamson (Identity and Discrimination ch.8), by contrast, if $I E_{a}$ is an individual essence, so should the analogous $I E$ ? be. By the way the argument above has been constructed, it would seem that this forces Williamson to abandon the idea that any of the $C P_{\mathrm{i}}$ properties are sufficient-for-existence properties. While this is an open theoretical option, it is neither Williamson's nor anything Williamson is committed to. Implicit in the argument above there is one further assumption: that $a$ and $b$ cannot be instantiators of $C P_{3}$ in the same world. This is the assumption that Williamson denies, paying, for it, the price of committing himself to coincident objects of the same kind — tables in this case ${ }^{16}$ — which would occupy the same spatio-temporal region, would share all non-modal properties, and would only be distinguished by their (slightly different) modal and essential properties. The other cost of this is that, when talking, for instance, about "the table in my room", this uniqueness condition is satisfied only to the extent that there is indeterminacy in reference-something with which Williamson is happy (Identity and Discrimination 133).

Among the friends of sufficient-for-existence properties, therefore, those who, in addition, would only accept inflexible essential properties will need to make neither Salmon's nor Williamson's choice, thereby being in a position to offer a neater metaphysical picture. Before drawing hasty conclusions in favour of strong-(EO), however, it would be worth exploring the extent to which this theoretical tidiness should be given any methodological weight—or, at any rate, more weight than the intuition supporting weak-(EO).

\section{Acknowledgements}

My great thanks to Anand Vaidya, Dan López de Sa, Fabrice Correia, Genoveva Martí, Manuel García-Carpintero and Tuomas Tahko, for their helpful comments on earlier drafts of this paper. With special mention, I am greatly thankful and indebted to Gabriel Uzquiano and an anonymous referee for this journal, whose penetrating comments helped me to understand better the issues discussed here. I can only hope to have reflected all this help in the final version.

\section{Works Cited}

Adams, Robert. 'Primitive Thisness and Primitive Identity'. Journal of Philosophy 76 (1979): 5-26.

\footnotetext{
${ }^{16}$ I am oversimplifying here. Strictly speaking, Williamson would object to the claim 'Williamson is committed to coincident tables' because, what we are calling here 'tables' is not exactly what Williamson calls 'tables'. Williamson's tables determinately satisfy that 'they are individuated by ranges of origin', but (for reasons orthogonal to vagueness) there is no range of origins such that, determinately, it individuates this (a particular) table. The latter is true, however, for what I am calling 'tables'. Let me call these more fine-grained entities 'tables*'. Williamson is committed to coincident tables* and, so phrased, he will agree with this claim too. The oversimplification in the main text is convenient for the sake of easiness of exposition-Williamson's tables* are our tables_-but, keeping this qualification in mind, it should be harmless.
} 
Boyd, R. 'Homeostasis, Species, and Higher Taxa'. Species: New Interdisciplinary Essays, Ed. Wilson, R. (1999): 141-185. Cambridge: MIT Press.

Brody, Baruch. 'Natural Kinds and Real Essences'. Journal of Philosophy 64 (1967): 431446.

Cameron, Ross. 'A Note on Kripke’s Footnote 56 Argument for the Essentiality of Origin'. Ratio XVIII (2005): 262-275.

Cameron, Ross and Roca, Sonia. 'Rohbraugh and deRosset on the Necessity of Origin'. Mind 115 (2006): 361-366.

Chisholm, Roderick. 'Identity Through Possible Worlds: Some Questions'. Noûs 1 (1967): 18.

Correia, Fabrice. '(Finean) Essence and (Priorean) Modality'. Dialectica 61/1 (2007): 63-84.

—_. 'Ontological Dependence'. Philosophy Compass 3.5 (2008): 1013-1032.

Damnjanovic, Nic. 'No route to Material Origin Essentialism?'. Erkenntnis 72/1 (2010): 93110.

Della Rocca, Michael. 'Essentialism versus Essentialism'. Conceivability and Possibility. Eds. T. Szabó Gendler and J. Hawthorne. Ofxord: Clarendon Press, 2002. 223-252.

Devitt, Michael. 'Resurrecting Biological Essentialism'. Philosophy of Science 75/3 (2008): 344-82.

Divers, John. 'Quinean Scepticism About De Re Modality After David Lewis'. European Journal of Philosophy. 15/1 (2006): 40-62.

Evnine, Simon. 'Modal Epistemology: Our Knowledge of Necessity and Possibility'. Philosophy Compass 3.4 (2008): 664-684.

Fine, Kit. 'Essence and Modality'. Philosophical Perspectives 8 (1994): 1-16.

Forbes, Graeme. The Metaphysics of Modality. Oxford: Clarendon Press, 1985

- ' 'Origins and Identities'. Individuals, Essence and Identity, Themes of Analytic Metaphysics. Eds. A. Bottani, M. Carrara, and P. Giarretta. Dordrecht: Kluwer. 2001. 319-340.

Forbes, Graeme and Robertson, Teresa. 'Does the New Route Reach its Destination?'. Mind 115(2006): 367-374.

Ghiselin, Michael. 'A Radical Solution to the Species Problem'. Systematic Zoology 23 (1974):536-544

Hawthorne, John and Gendler, Tamar. 'Origin Essentialism: The Arguments Reconsidered'. Mind 109/434 (2000): 285-298.

Hull, David. ‘A Matter of Individuality’. Philosophy of Science 45 (1978): 335-360.

Jubien, Michael. Possibility. Oxford: Oxford UP, 2009.

Kitcher, Philip. 'Species'. Philosophy of Science 51 (1984): 308-333.

Koslicki, Kathrin. 'Natural Kinds and Natural Kind Terms'. Philosophy compass 3/4 (2008): 789-802.

Kripke, Saul. Naming and Necessity, Cambridge, Massachusetts: Harvard UP, 1972/1980.

Lewis, David. On the Plurality of Worlds. Oxford: Basil Blackwell, 1986.

Linsky, Bernard and Zalta, Edward (1996). 'In Defense of the Contingently Nonconcrete'. Philosophical Studies 84 (1996): 283-294.

—. 'In Defense of the Simplest Quantified Modal Logic'. Philosophical Perspectives 8 (1994): 431-458.

Lowe, Jonathan. 'A Problem for A Posteriori Essentialism Concerning Natural Kinds'. Analysis 67.4 (2007): 286-92.

- The Possibility of Metaphysics. Substance, Identity and Time. Oxford: Oxford UP, 1998.

—. 'Two Notions of Being: Entity and Essence'. Being: Developments in Contemporary Metaphysics. Ed. Le Poidevin, Robin. Cambridge: Cambridge UP (2008): 23-48. 
Mackie, J.L. 'De What Re is De Re Modality?'. Journal of Philosophy 71 (1974): 551-561.

Mackie, Penelope. 'Essence, Origin and Bare Identity'. Mind 96 (1987): 173-201.

—. How Things Might Have Been: Individuals, Kinds and Essential Properties. Oxford: Clarendon Press, 2006.

. 'Identity, Time and Necessity'. Proceeding for the Aristotelian Society 98 (1998): 5978.

'Sortal Concepts and Essential Properties'. The Philosophical Quarterly 44 (1994): 311-33

Martí, Genoveva and Martínez, José. 'General Terms as Designators: A Defence of the View'. The Semantics and Metaphysics of Natural Kinds. Eds. H. Beebee and N. Sabbarton-Leary. New York: Routledge, 2010. 46-63.

McGinn, Colin. 'On the Necessity of Origins'. The Journal of Philosophy 73/5 (1976): 127135.

Mellor, Hugh. 'Natural Kinds'. British Journal for the Philosophy of Science 28 (1977): 299312.

Millikan, Ruth. 'Historical Kinds and the "Special Sciences"'. Philosophical Studies 95 (1999): 45-65.

Peacocke, Christopher. 'Principles for Possibilia'. Noûs, 36/3 (2002): 486-508.

Plantinga, Alvin. The Nature of Necessity. Oxford: OUP, 1974.

Putnam, Hilary. 'The Meaning of "Meaning"'. Minnesota Studies in the Philosophy of Science 7 (1975): 215-271. Reprinted in Mind, Language and Reality: Philosophical Papers, Vol.2. Cambridge: Cambridge UP.

Quine, Williard V. O. Word and Object. Massachutes: MIT Press, 1960.

Robertson, Teresa. 'Essentialism: Origin and Order’. Mind 108 (2000): 299-307.

—. 'Essential vs. Accidental Properties'. Stanford Encyclopedia of Philosphy. (Fall 2008 edition). Ed. Zalta, Edward. URL =

$<$ http://plato.stanford.edu/archives/fall2008/entries/essential-accidental/>.

—. 'Possibilities and the Arguments for Origin Essentialism'. Mind 107 (1998): 729-749.

Roca-Royes, Sonia. 'Essentialism vis-à-vis Possibilia, Modal Logic, and Necessitism'. Philosophy Compass, forthcoming.

—. 'Peacocke's Principle-Based account: Flexibility of Origins pus S4'. Erkenntnis 65/3 (2006): 405-426.

- Review of P. Mackie's How Things Might Have Been. Philosophical Review 118/2 (2009): 266-269.

Rohbraugh, Guy and deRosset, Louis. 'A New Route to the Necessity of Origin'. Mind 133 (2004): 705-725.

—. 'Prevention, Independence and Origin'. Mind 115 (2006): 375-386.

Salmon, Nathan. 'How Not to Derive Essentialism from the Theory of Reference'. The Journal of Philosophy 76/12 (1979): 703-725.

—. 'The Logic of What Might Have Been'. The Philosophical Review 98/1 (1989): 3-34.

- Reference and Essence, Princeton: Princeton UP, 1981.

Vaidya, Anand. 'The Epistemology of Modality'. The Stanford Encyclopedia of Philosophy (Fall 2008 Edition). Ed. Zalta, Edward. URL = <http://plato.stanford.edu/archives/fall2008/entries/modality-epistemology/>.

Wasserman, Ryan. 'Material Constitution'. The Stanford Encyclopedia of Philosophy (Spring 2009 Edition). Ed. Zalta, Edward. URL = $<$ http://plato.stanford.edu/archives/spr2009/entries/material-constitution/>.

Wiggins, David. Sameness and Substance. Oxford: Basil Blackwell, 1980.

—. Sameness and Substance Renewed. Cambridge: Cambridge UP, 2001.

Wikforss, Åsa Maria. 'Naming Natural Kinds’. Synthese 145/1 (2005): 65-87. 
Williamson, Timothy. 'Bare Possibilia'. Erkenntnis 48 (1998): 257-273.

—. Identity and Discrimination. Oxford: Basil Blackwell, 1990.

—. 'Necessitism, Contingentism, and Plural Quantification'. (ms.) Forthcoming in Mind.

Wilson, Jessica. 'Trope Determination and Contingent Characterization'. (ms.) URL:

http://individual.utoronto.ca/jmwilson/TDaCC.pdf. Accessed date: 06/03/2010.

Yablo, Stephen. 'Essentialism'. Routledge Enciclopedia of Philosophy. Ed. Craig, Edward. London: Routledge. 1998. 417-422.

Zalta, Edward. 'Essence and Modality’. Mind 115/459 (2006): 659-694. 